\title{
REFLEXÕES ACERCA DO ABUSO DE DROGAS E DA VIOLÊNCIA NA ADOLESCÊNCIA
}

\author{
Reflections concerning the drug abuse and the violence in the adolescence \\ Reflexiones a cerca del abuso de drogasy de la violencia en la adolescencia
}

Kelanne Lima da Silva ${ }^{1}$

Fernanda Lima Aragão Dias $^{2}$

Neiva Francenely Cunha Vieira ${ }^{3}$

Patrícia Neyva da Costa Pinheiro ${ }^{4}$

\section{RESUMO}

Estudo qualitativo que objetivou a realização de ações de Educação em Saúde visando à reflexão crítica dos adolescentes sobre o uso abusivo de drogas e consequentes comportamentos violentos. Realizado em uma escola pública de Fortaleza, com 23 adolescentes de 14 a 20 anos, nos meses de setembro e outubro de 2007. Adotou-se como referencial teórico-metodológico a pesquisa-ação. Os dados foram coletados durante a realização de quatro oficinas de grupo focal, juntamente com o diário de campo. Observou-se que os adolescentes experimentam as drogas por desinformação, curiosidade e fácil acesso. 0 uso de drogas pode desencadear a violência reconhecida por atitudes agressivas, o que limita sua compreensão. As estratégias de Educação em Saúde direcionadas aos adolescentes contribuem para um padrão de vida mais saudável, pois facilita a identificação dos fatores de riscos e tem a finalidade de reduzir a vulnerabilidade desses adolescentes.

palavras-chave: Educação em Saúde. Adolescente. Transtornos Relacionados ao Uso de Substâncias. Violência.

\begin{abstract}
Qualitative study that aimed the accomplishment of Health Education actions, seeking the adolescents' critical reflection about the drug abuse and consequent violent behaviors. Carried out at a public school of Fortaleza, with 23 adolescents from 14 to 20 years, in the months of September and October of 2007. It was adopted as theoretic and methodological reference the action research. The data were collected during the realization of four focus groups' workshops, together with the field journal. It was observed that the adolescents try drugs because of lack of information, curiosity and easy access. The drug use can unchain the violence recognized by aggressive attitudes, which limits the understanding. The strategies of Health Education addressed the adolescents contribute to a healthier living standard, because it facilitates the risk factors identification and it has the purpose of reducing those adolescents' vulnerability.
\end{abstract}

Keywords: Health Education. Adolescent. Substance-Related Disorders. Violence

\section{Resumen}

Investigación cualitativa con el objetivo de hacer acciones de Educación en Salud visando la reflexión crítica de los adolescentes sobre el uso demasiado de drogas y consecuentes comportamientos violentos. Hecho en una escuela pública de Fortaleza, con 23 adolescentes de 14 a 20 años, en los meses de septiembre y octubre de 2007. Se adoptó como referencial teórico y metodológico la investigación-acción. Los datos fueron colectados durante los talleres de grupo focal, juntamente con el guía de campo. Se observó que los adolescentes experimentaron las drogas por falta de información, curiosidad y fácil acceso. El uso de drogas puede resultar en violencia que es reconocida por conductas agresivas, lo que disminuye su comprensión. Las estrategias de Educación en Salud direccionadas a los adolescentes contribuyen para un padrón de vida más sano, pues mejoran la identificación de los factores de riesgos y tiene la finalidad de reducir la vulnerabilidad de eses adolescentes.

palabras clave: Educación en Salud. Adolescente. Trastornos Relacionados con Sustancias. Violencia.

\footnotetext{
'Acadêmica de Enfermagem da Universidade Federal do Ceará. Integrante do Projeto de Pesquisa "AIDS: Educação e Prevenção, e bolsista do Projeto de Pesquisa: Desmistificando crenças e valores de adolescentes do sexo masculino em favor da prevenção de DST/AIDS", financiado pela FUNCAP/CNPq/PPP. Fortaleza-CE-Brasil. E-mail: lany_Ids@hotmail.com, ${ }^{2}$ Enfermeira especialista em Enfermagem Clínica do Hospital Infantil Albert Sabin, localizado em FortalezaCE. Mestranda do Curso de Mestrado em Enfermagem da Universidade Federal do Ceará - UFC. Integrante do Projeto de Pesquisa "AIDS: Educação e Prevenção" da UFC.Fortaleza-CE-Brasil. E- mail: ferlimara@yahoo.com.br, ${ }^{3}$ Enfermeira, PhD pela Universidade de Bristol. Professora Adjunta da Universidade Federal do Ceará. Coordenadora do Projeto de Pesquisa "A tecnologia educacional e os modelos de Educação em Saúde nas ações de enfermagem e promoção da saúde". CNPq. Processo: 409365/2006-8.Fortaleza-CE-Brasil. E-mail: neiva_cunha@pesquisador.cnpq.br ,'Enfermeira, Doutora em Enfermagem. Professora Adjunta da Universidade Federal do Ceará. Coordenadora do Projeto de Pesquisa "Desmistificando crenças e valores de adolescentes do sexo masculino em favor da prevenção de DST/AIDS". FUNCAP/CNPq/PPP. Processo: 0006-00/2006.Fortaleza-CE-Brasil. E-mail: neyva.pinheiro@bol.com.br
} 


\section{INTRODUÇÃO}

0 uso abusivo de drogas lícitas e ilícitas pode ser considerado um dos principais problemas de saúde pública na sociedade atual. Dentre os diversos danos sociais relacionados ao consumo de drogas, destacam-se os acidentes de trânsito, os prejuízos escolares e ocupacionais, assim como a violência, caracterizada pela ocorrência de brigas, homicídios e a prática de atos ilícitos, que pode ser ocasionada pelo efeito dessas substâncias. Além de todos esses agravos, a droga pode ainda proporcionar alterações físicas e mentais. ${ }^{1}$

Os adolescentes e os adultos jovens destacam-se como a população mais envolvida no consumo de drogas, pois enfrentam, nessa fase do desenvolvimento humano, modificações físicas, comportamentais e emocionais. ${ }^{~}$ É também nessa faixa etária que o indivíduo se identifica com um grupo específico, passando a pertencer a este. Assim, em virtude dessas alterações, do relacionamento intergrupal e da influência do meio externo, o adolescente se encontra vulnerável ao uso abusivo de drogas lícitas e ilícitas, que pode desencadear comportamentos violentos. Podem ser citados como fatores que predispõem o abuso dessas substâncias na adolescência: 0 contato com familiares etilistas e drogaditos que agem com autoridade ou permissividade; amigos usuários de drogas; a presença de comportamentos antissociais; a baixa autoestima apresentada pelos jovens; acesso fácil às drogas e a história de abuso sexual. ${ }^{2}$

Como dito anteriormente, o abuso de drogas pode estimular comportamentos violentos, mas, além do uso dessas substâncias, os adolescentes se encontram, muitas vezes, expostos a ambientes que favorecem a violência, a qual pode se manifestar por diversos meios, por exemplo: internet, programas de televisão, filmes em geral, inclusive desenhos infantis que não se adequam à faixa etária das crianças. Algumas estimativas comprovam que um jovem de 20 anos já assistiu a 25.000 mortes e 200.000 atos de violência veiculados pela mídia. ${ }^{3}$ Isso interfere no desenvolvimento da personalidade dos adolescentes, induzindo-os a apresentar atitudes violentas.

Com isso, justifica-se a necessidade de realizar atividades educativas com 0 apoio de importantes setores sociais, como a escola e as unidades de saúde, que carecem de medidas preventivas direcionadas aos riscos a que a população dessa faixa etária está exposta, pois muitos dos adolescentes não apresentam fontes esclarecedoras de suas dúvidas. ${ }^{1}$

Ressalta-se a importância no desenvolvimento de atividades educativas com os adolescentes, abordando temáticas como uso abusivo de drogas e violência pelo enfermeiro, de maneira a proporcionar uma construção compartilhada do conhecimento, a conscientizar os jovens sobre a adoção de um estilo de vida saudável, a propiciar momentos de reflexão crítica acerca de temáticas polêmicas e cotidianas como o uso de drogas e situações vivenciadas ou observadas de violência. ${ }^{4}$
0 interesse em desenvolver um estudo com adolescentes teve origem na suposição de que são indivíduos que enfrentam várias modificações de natureza diversificada e se expõem a situações de riscos, como o uso abusivo de drogas e a violência, que se destacam por acarretarem prejuízos de ordem física, social e emocional.

Esse estudo contribuirá para o pensamento críticoreflexivo voltado para a prevenção das drogas e violência e também fornecerá subsídios ao desenvolvimento de projetos a serem executados em instituições de ensino, possibilitando mudanças nos modos de pensar e agir dos adolescentes e, consequentemente, a melhoria da qualidade de vida desses cidadãos.

Diante do exposto, objetivou-se realizar o presente estudo com ações de Educação em Saúde visando à reflexão crítica dos adolescentes sobre as questões relacionadas com 0 uso abusivo de drogas e comportamentos violentos.

\section{METOLOGIA}

Trata-se de uma pesquisa-ação, que aprimora a técnica pela oscilação sistemática entre a ação no campo da prática e a investigação a respeito dela. Assim, planeja-se, implementase, descreve-se e avalia-se, aprendendo mais, no correr do processo, tanto a respeito da prática quanto da própria investigação. ${ }^{5}$

A população da pesquisa foi composta por 10 alunos do sexo masculino e 13 do feminino de 14 a 20 anos de idade, que estudam no $1^{\circ}$. ano do ensino médio de uma escola pública pertencente à Secretaria Executiva Regional III, do município de Fortaleza-CE, vinculada ao projeto de extensão do Departamento de Enfermagem da Universidade Federal do Ceará (UFC), cuja temática é "AIDS - Educação e Prevenção", no decorrer dos meses de setembro e outubro do ano de 2007.

Os dados foram coletados durante a realização de quatro oficinas de grupo focal, juntamente com o diário de campo, no qual foram registrados os resultados obtidos da aplicação dessas oficinas, trabalhando temas sugeridos pela diretoria da escola e apontados pelos adolescentes como pertencentes a sua área de interesse e de curiosidades. Com efeito, foram empreendidos momentos de debate sobre os assuntos e formulação de conhecimentos, envolvendo crenças, atitudes e ideias dos adolescentes acerca do uso abusivo de drogas e violência, por meio de encontros que tiveram a duração, em média, de quatro horas cada um.

A análise dos dados foi procedida de acordo com 0 apontado por Leopardi, ${ }^{6}$ sobretudo quanto a dimensões que surgiram com relação à área temática, destacando as divergências e convergências surgidas no desenvolvimento da pesquisa, a síntese de todos os temas ou propostas discutidas no universo do grupo dentro da temática e, finalmente, a síntese global do conteúdo das reuniões grupais, enfocando os principais objetivos da pesquisa e as decisões e ações a efetivar. 
Foram respeitados os aspectos éticos presentes nos ditames da Resolução n ${ }^{\circ}$ 196/96, do Conselho Nacional de Saúde - MS/Brasil, e e o Comitê de Ética em Pesquisa da Universidade Federal do Ceará aprovou o projeto ao emitir parecer favorável mediante a expedição do ofício de no. 152/ 09 e do protocolo de no. 118/09

\section{RESULTADOS}

Os resultados serão apresentados de acordo com os temas abordados durante as ações de Educação em Saúde feitas na escola e direcionadas à prevenção do uso de drogas e da violência. Assim, serão enfatizadas as questões relacionadas à vulnerabilidade dos adolescentes com o intuito de minimizar os riscos aos quais eles estão expostos.

\section{Drogas na visão dos adolescentes}

Os estudos 8 apontam que o primeiro contato com a droga geralmente ocorre na adolescência, por ser uma etapa do ciclo evolutivo marcada por transformações físicas e psíquicas, que tornam o adolescente mais vulnerável do ponto de vista psicológico e social. Além disso, essa fase é considerada como crucial na formação de hábitos de conduta e de modelos de socialização, podendo ocorrer nela o estabelecimento de padrões estáveis de comportamento, o que favorece o consumo de drogas e 0 aparecimento precoce de problemas referentes à saúde. $^{9}$

0 consumo de drogas na adolescência constitui grave problema social e de saúde pública, não só no Brasil como também em outros países, apresentando como fatores predisponentes os relacionados com o ciclo de amizade, relações familiares, aspectos individuais, a comunidade de convivência e a mídia. ${ }^{9}$

Segundo os adolescentes pesquisados e em concordância com as ideias dos autores referidos anteriormente, o jovem experimenta droga em decorrência da desinformação; curiosidade; insatisfação com a vida; insegurança; despersonalização; frustrações e fácil acesso.

0 primeiro contato com as drogas ocorre principalmente pelo fato de os adolescentes terem amigos que usam drogas, ocasionando uma pressão de grupo na direção do uso. No que concerne à situação familiar, trauma familiar, separaç̧ão, brigas e agressões estão associados ao grupo de adolescentes com maior probabilidade de se tornarem dependentes. ${ }^{9}$

Os mais potentes preceptores de uso frequente de drogas são as variáveis individuais relacionadas a um estilo de vida não convencional, dentre elas: a busca de sensações, rebeldia, tolerância a comportamentos desviantes, baixa autoestima, sintomas depressivos, eventos de vida estressantes e baixa escolaridade. ${ }^{8}$

A disponibilidade e a presença de drogas na comunidade de convivência são vistas como facilitadoras do uso de drogas por adolescentes, uma vez que o excesso de ofer ta naturaliza 0 acesso. ${ }^{7}$ Isso foi bastante evidenciado durante a realização do grupo focal, pois os adolescentes relataram que próximo às suas residências, havia "bocas de fumo", e os viciados ficavam usando droga em qualquer lugar. Mostraram saber como usar, fabricar e outras denominações que são dadas às drogas, segundo as seguintes falas:

Na esquina da minha casa tem uma boca de fumo e de longe dá pra sentir o cheiro da droga; existe muita droga por aí: mesclado, que é maconha com cocaína; aranha é um comprimidinho que se toma com bebida; ainda existe mais só que as mais conhecidas são o pó e a maconha. Nas calçadas fica um monte de gente, enrolando a maconha no papel pra fumar ou cheirando cocaína; a cocaína vem em pedra, aí você derrete no fogo e fica parecendo farinha... (A1).

Em relação à mídia, é possível levantar uma série de propagandas de bebidas alcoólicas, particularmente de cerveja, que são diariamente exibidas. Esses comerciais costumam ser chamativos, sendo associados a situações divertidas, envolvendo jovens e lazer. ${ }^{9}$ Esse fato influencia os adolescentes que referiram já haver experimentado bebida alcoólica, seguida por cigarro e maconha, de acordo com a enquete realizada com os jovens que participaram da pesquisa. Diferentes estudos, nacionais e estrangeiros, sistematicamente confirmam a impressão genérica de que, se o álcool é facilmente obtido e fartamente propagandeado, isto se reflete em seu consumo precoce e disseminado. ${ }^{10}$

0 álcool é a substância mais consumida entre os jovens, sendo que a idade de início de uso tem sido cada vez menor, aumentando o risco de dependência futura. 0 uso de álcool na adolescência está associado a uma série de comportamentos de risco, além de aumentar a chance de envolvimento em acidentes, violência sexual, participação em gangues, queda no desempenho escolar, dificuldades de aprendizado, prejuízo no desenvolvimento e estruturação das habilidades cognitivo-comportamentais e emocionais dojovem. Dados nacionais apontam para uma associação entre uso de álcool, maconha e comportamentos sexuais de risco com o início precoce de atividade sexual, não uso de preservativos, pagamento por sexo e prostituição. ${ }^{10}$

Os adolescentes conhecem os efeitos das drogas e concordam com o fato de que o seu uso faz mal à saúde, mas disseram que não acreditavam que ficariam viciados se utilizassem às vezes. Alguns jovens também citaram consequências do uso da droga, como:

A pessoa que se envolve com drogas sai da escola, perde a familia e os amigos; fica uma pessoa violenta; rouba, se prostitui, mata ou faz qualquer coisa para comprar droga; A pessoa vai perdendo o sentido da vida e a vida se torna uma droga... (A2). 
Formas atrativas de ocupar o tempo livre dos adolescentes, a interação e o bom diálogo com os pais e a participação nas atividades escolares e religiosas podem diminuir o risco de envolvimento dos jovens com as drogas. ${ }^{9} \mathrm{De}$ acordo com os adolescentes que participaram da oficina, a única maneira de evitar o envolvimento com as drogas é a informação, segundo os relatos a seguir:

Quando a pessoa sabe o que a droga pode fazer de ruim, ela fica com medo e tenta não se viciar. Acredito que todo mundo conhece o mal que a droga causa, mas não acredita que usando às vezes vai acontecer algo ruim, por isso que é importante saber sobre esse assunto... (A3).

As estratégias utilizadas em Educação em Saúde, que favorecem a reflexão e o conhecimento acerca da gravidade das drogas, podem contribuir para um padrão de vida mais saudável e ser direcionadas às consequências dos riscos aos quais os adolescentes estão expostos, pois o uso abusivo de drogas, especialmente do álcool, que mostrou ser o mais consumido entre os jovens, pode desencadear comportamentos violentos. Estatísticas internacionais apontam que, em cerca de $15 \%$ a $66 \%{ }^{11}$ de todos os homicídios e agressões sérias, 0 agressor, a vítima, ou ambos, tinham ingerido bebidas alcoólicas. Da mesma maneira, o consumo de álcool está presente em cerca de $13 \%$ a $50 \%{ }^{11}$ dos casos de estupro e atentados ao pudor.

As atividades de educação em saúde serão mais efetivas e obterão resultados mais promissores se o educador, e mais precisamente o enfermeiro, considerar o adolescente como inserido em um contexto socioeconômico e familiar que exerce muitas influências no seu modo de pensar e agir, sendo fatores determinantes e condicionantes no seu comportamento, no modo de cuidar de sua saúde e na adoção de um determinado estilo de vida. Diante disso, considera-se fundamental a atuação do enfermeiro na promoção da saúde dos adolescentes em relação ao uso abusivo de drogas, inserindo a familia e os amigos como participantes das atividades de educação em saúde, visto que estes setores sociais são referidos como exemplos de modelo de conduta e de vida pelos adolescentes. ${ }^{12}$

\section{adolescentes}

Os tipos de violência e 0 entendimento dos

A violência constitui fenômeno que atinge diretamente a saúde pública porque afeta a saúde individual e coletiva, exigindo a formulação de políticas e organização de práticas e de serviços específicos para sua prevenção. Quanto aos jovens, é justamente nesse grupo que se concentram as mais altas taxas de morte por agressão, bem como são os maiores acusados de autoria de violência. ${ }^{13} \mathrm{~A}$ cada 100 mil ocorrências, cerca de $70 \%$ de todos os homicídios ocorrem com adolescentes. ${ }^{11}$
A violência é geralmente reconhecida pelos adolescentes por atos como assassinatos, brigas, entre outros, o que limita sua compreensão para a ação que provoca a morte ou um dano visível.

Durante a realização da oficina, os facilitadores, utilizando fotos, tentaram abordar alguns tipos de violência, como social, sistêmica, econômica, psicológica, ambiental, corporal, física, sexual, de gênero, racial e intrafamiliar. Quando se começou a mostrar as figuras, os adolescentes se mostraram surpresos com tanto tipo diferente de violência, mas aos poucos eles mesmos começaram a citar exemplos.

A violência social refere-se às condições injustas da sociedade para com a parcela mais desfavorecida de sua população. A pobreza é a pior forma de violência. ${ }^{11}$ Alguns adolescentes comentaram a respeito desse tipo de violência, dizendo que não pensavam que a pobreza era violência e, de acordo com isso, citaram um exemplo:

Tem um aleijadinho que fica sempre sentando debaixo daquele viaduto, ele vive sujo, chega é preto da fumaça dos carros, eu fico com muita pena dele (A4).

A violência sistêmica brota da prática do autoritarismo. ${ }^{11}$ A violência policial é um exemplo. Nesse momento, quase todos tinham algo a falar da polícia e contavam fatos que haviam acontecido com eles ou com amigos, conforma a fala a seguir:

Esses policiais são muito brutos, já chegam chamando de vagabundo; meu vizinho uma vez levou uma porrada de um policial só porque tava rindo e ele achou que era com ele (A5).

A violência econômica são todos os atos destrutivos ou omissões do(a) agressor(a) que afetam a saúde emocional e a sobrevivência. Pode-se mencionar como exemplos: roubo, destruição de bens pessoais, recusa de pagar a pensão alimentícia e uso dos recursos econômicos da pessoa idosa, tutelada ou incapaz, destituindo-a do gerenciamento de seus próprios recursos. ${ }^{11}$ Em todos esses exemplos, os adolescentes tinham algo a contar, principalmente sobre roubo e pensão alimentícia. Talvez esses exemplos estejam bem presentes no cotidiano deles, como o apresentado a seguir:

Lá perto da minha casa todo dia tem roubo, principalmente de bicicleta e celular; assalto tem todo dia, é só ligar a televisão e você fica sabendo de inúmeros assaltos (A6).

A violência psicológica é uma situação percebida nos relatos de onde há disciplina mental abusiva, chegando à prática de ameaças e humilhações. ${ }^{11}$ Nesse momento, alguns 
adolescentes diziam já ter sofrido esse tipo de violência e que ela ocorria em todo lugar, como a seguinte citação:

A maioria das pessoas gostam de humilhar as outras. As pessoas gostam de colocar apelido, então quando você não gosta é um tipo de violência psicológica (A7).

A violência ambiental são ações que prejudicam o ambiente. ${ }^{14}$ Alguns adolescentes citaram que nunca imaginaram que jogar lixo no chão seria violência.

Já vi que todo mundo é violento, pois todo dia todo mundo joga lixo nas ruas; por isso o planeta está se acabando, pois não cuidamos bem dele, e aí está o aquecimento global (A8).

A violência corporal é a percepção que mede os cuidados com a saúde física, nutrição, vestuário, higiene pessoal e vigilância quanto à proteção em qualquer ambiente. ${ }^{11}$ Os adolescentes comentavam sobre as modelos e também citaram uma novela que tinha uma garotinha que tudo que comia vomitava.

A violência física ocorre quando uma pessoa que desempenha relação de poder sobre a outra causa, ou tenta causar, dano não acidental, por meio do uso da força física ou de algum tipo de arma que pode provocar ou não lesões externas, internas ou ambas. ${ }^{11}$ Muitos adolescentes disseram achar que violência era apenas a física.

Essa violência é direto passando na tv. Tem cada caso que passa nesses programas criminais (A9).

A violência sexual compreende uma variedade de atos ou tentativas de relação sexual sob coação ou fisicamente forçada, no casamento ou em outros relacionamentos. Como violência sexual, pode-se mencionar: sugestões sexuais, assédio sexual, exibicionismo, incitação sexual, penetração, exploração sexual comercial e turismo sexual..$^{15}$

Tinha um homem que vivia na esquina perto da minha casa, e, quando as mulheres passavam, ele colocava as coisas para fora. Isso é violência e eu nem sabia, achava que era falta de vergonha na cara. Graças a Deus, eu nunca fui estuprada, mas deve ser horrivel; um homem que estupra uma mulher é um maníaco e precisa de um bom castigo (A10).

A violência de gênero consiste em qualquer ação ou conduta, baseada no gênero, que cause morte, dano ou sofrimento físico, sexual ou psicológico à mulher e ao homem, tanto no âmbito público como no privado. A violência de gênero é uma manifestação de relação de poder historicamente desigual entre homens e mulheres, em que a subordinação não implica a ausência absoluta de poder. ${ }^{16} 0$ s adolescentes comentaram muito sobre a Lei Maria da Penha, que cria mecanismos para coibir a violência doméstica e familiar contra a mulher, nos termos do $\S 8^{\circ}$ do art. 226 da Constituição Federal, da Convenção sobre a Eliminação de Todas as Formas de Discriminação contra as Mulheres e da Convenção Interamericana para Prevenir, Punir e Erradicar a Violência contra a Mulher. ${ }^{17}$

A violência racial é o preconceito. A maioria relatou exemplos de preconceitos, principalmente com negros.

Na televisão sempre passa exemplos de racismos, e os negros com certeza são os mais atingidos por essa violência (A11).

A violência doméstica distingue-se da violência intrafamiliar por incluir outros membros do grupo, sem função parental, que convivam no espaço doméstico. As agressões domésticas incluem: abusos físicos, sexuais e psicológicos, a negligência e 0 abandono. ${ }^{17}$ Nesse momento, os adolescentes também reconheceram muitos exemplos, como de babás e pais que batem nas crianças, crianças abandonadas e os abusos que as crianças sofrem dentro de casa.

Entre os maus-tratos contra o adolescente, destacam-se: abuso físico, sexual e psicológico. Também se afigura nesse elenco 0 abandono que expõe 0 adolescente a situações de risco e à negligência, que implica privá-lo daquilo que precisa para seu crescimento e desenvolvimento (alimentos, vestimenta, habitação, medicamentos, escola, lazer, segurança, afeto, entre outros). ${ }^{18}$

As experiências com a família e com a sociedade conferem aos adolescentes aprendizagem para o futuro, formando seus conceitos e valores e constituindo padrões de referência. Dessa forma, a abordagem deve ser multidisciplinar e envolver, além da vítima, a família e recursos da comunidade a fim de evitar recidivas. ${ }^{18}$

Esse diálogo com os adolescentes propiciou uma reflexão crítica sobre o assunto e um aprendizado no que se refere aos tipos de violência; isso mostra a importância desses momentos para minimizar ou erradicar a violência da sociedade. Assim, destaca-se a importância do desenvolvimento dos programas de forma integrada, atuando nos âmbitos individual, familiar, comunitário e social. É relevante o papel da escola em estruturar condições para garantir maior permanência dos adolescentes dentro do ambiente escolar por meio de esportes e outras atividades. ${ }^{17}$ 


\section{CONSIDERAÇÕES FINAIS}

Realizar ações de Educação em Saúde durante a adolescência, fase da vida que impõe transformações e interferências do meio social e familiar, é um grande desafio. As mudanças que ocorrem durante a adolescência fazem com que os adolescentes tentem se rebelar contra a realidade vivenciada, manifestando-se com o uso da sua sexualidade de forma inconsequente, da ingesta de drogas e de práticas de violência.

As estratégias utilizadas em Educação em Saúde devem envolver o adolescente, a família e a sociedade, pois essas táticas auxiliam os adolescentes nas experiências futuras, formando seus conceitos e valores e formando padrões de referência.

Assim, foi possível perceber a diferença de conhecimento dos adolescentes antes e após intervenções dos autores acerca das implicações que o uso das drogas pode trazer para suas vidas, bem como os diferentes tipos de violência aos quais esses jovens podem estar sujeitos. Os adolescentes mostraramse receptivos ao diálogo, colaborando para a troca de ideias, e, dessa forma, conseguiu-se corrigir informações distorcidas que eles detinham com relação às drogas e à violência.

Acredita-se que o presente trabalho, de alguma forma, contribuiu para proporcionar reflexões e um maior entendimento acerca do uso de drogas e tipos de violência nos adolescentes, uma vez que o conhecimento dos fatores desencadeadores desse consumo e da violência, bem como de suas consequências, podem fazer com que os jovens se conscientizem dos malefícios que eles acarretam em suas vidas e tornem-se cidadãos conscientes e multiplicadores de hábitos saudáveis.

\section{REFERÊNCIAS}

1-Gil HLB, Melo DF, Ferriani MGC, et al. Opinião de adolescentes estudantes sobre consumo de drogas: um estudo de caso em Lima, Peru. Rev Latino-am Enfermagem 2008 jul/ago; 16( nesp): 551-57.

2- Silva EF, Pavani RAB, Moraes MS, Neto FC. Prevalência do uso de drogas entre escolares do ensino médio do município de São Jose do Rio Preto, São Paulo, Brasil. Cad Saude Publica 2006 jun; 22(6): 1151-58

3- Oria FU. Promoção de segurança da criança e do adolescente frente à mídia. Documento Cientifico da Sociedade Brasileira de Pediatria. Segurança da criança e do adolescente; 2001.

4- Beserra EP, Pinheiro PN, Barroso MGT. Ação educativa do enfermeiro na prevenção de doenças sexualmente transmissíveis: uma investigação a partir das adolescentes. Esc Anna Nery Rev Enferm 2008 set; 12(3): $522-28$.

5- Tripp D. Pesquisa-ação: uma introdução metodológica. Educ Pesqui 2005 dez; 31(3): 443-66.
6- Leopardi MT. Metodologia da pesquisa na saúde. Santa Maria (RS): Pallotti; 2001.

7- Resolução n¹96, de 10 de outubro de 1996. Dispõe sobre a realização de pesquisas com seres humanos. Brasilia (DF): Conselho Nacional de Saúde; 1996.

8-Sanceverino SL, Abreu JLC. Aspectos epidemiológicos do uso de drogas entre estudantes do ensino médio no município de Palhoça 2003. Cienc Saude Colet 2004 out/dez; 9(4): 1047-56.

9- Rebolledo EAO, Medina NMO, Pillon SC. Factores de riesgo asociados al uso de drogas em estudiantes adolescentes. Rev Latino-am Enfermagem 2004 mar/abr; 12 (nesp): 369-75.

10- Pechanskya F, Szobota CM, Scivolettob S. Uso de álcool entre adolescentes: conceitos, características epidemiológicas e fatores etiopatogênicos. Rev Bras Psiquiatr 2004 maio; 26 (supl 1):14-17.

11- Schraiber LB, D'Oliveira AFPL, Couto MT. Violence and health: recent scientific studies. Rev Saude Publica [on-line]. 2006 ago [citado 22 set 2008 ]; 40 ( $n^{0}$ esp): 112-20. Disponível em: http://www.scielo.br

12- Cavalcante MBPT, Alves MDS, Barroso MGT. Adolescência, álcool e drogas: uma revisão na perspectiva da promoção da saúde. Esc Anna Nery Rev Enferm 2008 set; 12(3): 555-59.

13- Ministério da Saúde (Br). Impacto da violência na saúde dos brasileiros. Brasília (DF); 2005.

14- Ribolla MB, Fiamenghi JR., Geraldo A. Adolescentes na escola: representações sociais sobre violência. Psicol Esc Educ [on-line]. 2007 jun [citado 22 set 2008]; 11 (1): 111-21. Disponivel em http://uww.scielo.br

15- Ribeiro MA, Ferriani MGC, Reis JN. Violência sexual contra crianças e adolescentes: características relativas à vitimização nas relações familiares. Cad Saude Publica 2004 mar/abr; 20(2): 456-64

16-Rocha CR, Siqueira PRA, Oliveira PRF, et al A enfermagem e a saúde da mulher: questões de gênero e sociopolíticas. Esc Anna Nery Rev Enferm $2000 \mathrm{abr} ; 4(1)$ : 105-14.

17- Ministério da Saúde (BR). Violência intrafamiliar: orientações para a prática em serviço. Brasília (DF); 2002.

18-Cardoso ES, Santana JSS, Ferriani MGC. Criança e adolescente vítima de maus-tratos: informações dos enfermeiros de um hospital público. Rev Enferm UERJ 2006 out/dez; 14(4): 524-30. 